\title{
Intrinsic vulnerability in the global fish catch
}

\author{
William W. L. Cheung ${ }^{1, *}$, Reg Watson $^{1}$, Telmo Morato ${ }^{1,2}$, Tony J. Pitcher $^{1}$, Daniel Pauly ${ }^{1}$ \\ ${ }^{1}$ Fisheries Centre, The University of British Columbia, Aquatic Ecosystems Research Laboratory (AERL), 2202 Main Mall, \\ Vancouver, British Columbia V6T 1Z4, Canada \\ ${ }^{2}$ Departamento de Oceanografia e Pescas, Universidade dos Açores, 9901-862 Horta, Portugal
}

ABSTRACT: We have identified the marine fish taxa that are most vulnerable to exploitation, by compiling an index of intrinsic vulnerability based on life history traits. Since 1950, the global fish catch has been increasingly dominated by species with low intrinsic vulnerability, indicated by a decline in mean vulnerability of the taxa in the catches. This decline is strongest in catches of coral reef fishes, probably as a result of overexploitation of the more vulnerable species. The change is less apparent in estuaries, where fish communities are more transient. The opposite is observed at seamounts, where more vulnerable species have become exploited and serially depleted in recent years. Rates of change in the mean vulnerability index in the catches from different areas are negatively correlated with the number of threatened fishes on the IUCN Red List. Particularly, catches from the Indo-Pacific and Caribbean regions are characterized by a high abundance of threatened fishes and by strong declines in the mean vulnerability index. Our findings suggest that fishing largely alters the community structure of coral reef fishes, which may detrimentally affect the ecosystem. Attention should also be given to deep water demersal and benthopelagic fish assemblages, especially those around seamounts, which are intrinsically vulnerable to fishing. The index of intrinsic vulnerability thus provides a novel tool for fisheries management and conservation.

KEY WORDS: Intrinsic vulnerability - Fishing • Marine conservation . Coral reef • Estuary . Seamount

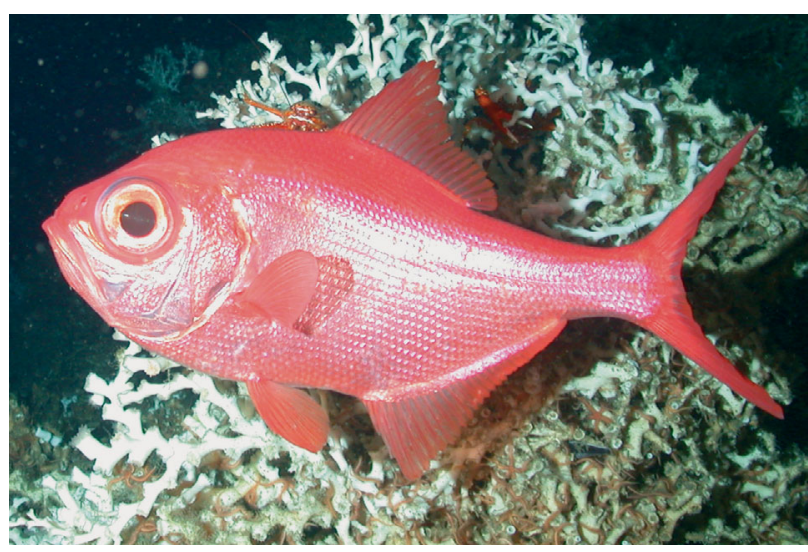

Average intrinsic vulnerability of taxa in global catches has declined since the 1950s, as less vulnerable species become increasingly dominant. Such changes are most apparent in coral reefs, where fish communities were once relatively stable. Serial exploitation of the highly vulnerable fishes of seamounts (e.g. alfonsino Beryx decadactylus) does not appear to be sustainable.

Photo: S. W. et al. Ross (2004)

\section{INTRODUCTION}

Fishing is a major agent of disturbance to marine ecosystems (Pauly et al. 2002). It has caused a general decline in fish biomass, and placed many marine species under serious conservation concern (e.g. Casey \& Myers 1998, Baum et al. 2003, Dulvy et al. 2003, Sadovy \& Cheung 2003). Of the marine fishes that are listed in the IUCN Red List of Threatened Species (Baillie et al. 2004), the majority are endangered directly or indirectly by fishing (Dulvy et al. 2003). 
The life history of a fish species affects its vulnerability to fishing - a feature here called 'intrinsic vulnerability' (Dulvy et al. 2003, Cheung et al. 2005). Generally, species with larger body size (maximum body length or asymptotic length), higher longevity, higher age at maturity, and lower growth rates have higher vulnerability to fishing (Jennings et al. 1999a,b, Reynolds et al. 2005a). Species with these life history traits should be less able to sustain high fishing mortality. Thus differences in life history result in structural changes in the exploited fish community (Jennings et al. 1999a). In this paper, a community is defined as the species that occur together in space and time (Begon et al. 2005).

Empirical studies using historical abundance data of exploited fish populations found significant correlations between the rate of population declines (a proxy of vulnerability to fishing) and life history parameters such as maximum body size and age at maturity, but not fecundity (Dulvy et al. 2003, Reynolds et al. 2005a). Also, meta-analysis using 54 stock-recruitment timeseries showed that large, late-maturing fishes had strong density-dependence at low abundance, but high maximum recruitment when unexploited (Goodwin et al. 2006). Thus a fishery targeting fishes with such life histories can be initially productive (when fishing effort is low and fish abundance is still high), but become highly susceptible to collapses when abundance is greatly reduced by fishing. Current evidence suggests that body size is one of the most important factors in determining vulnerability to fishing (Jennings et al. 1998, 1999a, Reynolds et al. 2005b).

The correlations between life history and vulnerability to fishing may explain the serial depletion of fish populations, with fishing activities in heavily exploited areas progressing from large-bodied species that tend to have high vulnerability to species with less vulnerable life histories (Pauly et al. 1998, 2002, Pitcher 2001). More vulnerable species decline faster in abundance given similar fishing rates and thus are more readily over-exploited (Jennings et al. 1998, 1999a, Cheung et al. 2005). Therefore, the change in relative abundance of vulnerable species can be reflected in the catch composition. In fact, serial replacement of intrinsically more vulnerable by less vulnerable species may be the reason for the 'fishing down marine food webs' phenomenon (Pauly et al. 1998), as fishing generally targets large predatory (often intrinsically more vulnerable) species, but progressively moves to lower trophic level species (often less vulnerable) as the predatory species become over-exploited. On the other hand, it has been argued that the apparent increase in dominance of low trophic level species in marine catches in some ocean basins might be the result of mere expansion of fisheries to the lower trophic level species, without reduction of the catches of predatory species (Essington et al. 2006). Understanding the relationship between intrinsic vulnerability and changes in catch composition may provide insights to this debate.

Different life history traits are evolved to adapt to different environments or habitats (Charnov 1993, Vila-Gispert et al. 2002, Winemiller 2005). For instance, many of the coral reef and seamount fishes are thought to be particularly vulnerable to fishing because of life history traits such as slow growth and late maturation (Koslow et al. 2000, Sadovy 2005, Morato et al. 2006a). Particularly, coral reef fishes depend strongly on coral reef for refuges (Sale 1977). This renders them more vulnerable to direct and indirect impacts from habitat damages (e.g. use of destructive fishing methods). Estuarine fishes, on the other hand, have a mixture of life history strategies that are adapted to both fluctuating estuarine environments and more stable marine inshore habitats (Whitfield 1990, Blaber 2000, Roessig et al. 2004). Their communities include a mixture of diadromous, marine and freshwater migratory and estuary resident fishes (Blaber 2000). The relationships between the life history characteristics and the effects of the threats on the estuarine populations may vary widely between species (Reynolds et al. 2005a). Thus, effects of fishing on the structure of coral reef and seamount fish communities may appear to be stronger than the effects on estuarine fish communities.

Given the different characteristics of fish communities in different habitats and the threats of fishing to them, it would be useful to understand the intrinsic vulnerability of fishes in these communities. Also, tracking and comparing the impacts of fishing on these communities over time could increase understanding of the current conservation status and formulate conservation and fisheries management strategies. Intrinsic vulnerability may be predicted from life history traits (Cheung et al. 2005, Reynolds et al. 2005a) while the effects of fishing on the fish communities may be tracked by evaluating changes in composition of catch over time.

This study attempted to test 2 hypotheses. (1) We tested if marine fish species that are adapted to different environments have different vulnerabilities to fishing. Specifically, we evaluated whether coral reef and seamount fish communities were intrinsically more vulnerable to fishing than estuarine fish communities. To do this, based on the life history information available from Fishbase (Froese \& Pauly 2004), an index of intrinsic vulnerability to fishing was calculated for all marine fish taxa. We employed regression analysis to evaluate how habitats and distributions of fishes relate to their intrinsic vulnerability. (2) We investigated if 
changes in the species composition of catches were related to the intrinsic vulnerability of the exploited taxa. We discussed the relative intrinsic vulnerability of fishes and their overall conservation status in the major habitats.

\section{MATERIALS AND METHODS}

Predicting species intrinsic vulnerability. Using a fuzzy logic expert system (Cheung et al. 2005), an index of the intrinsic vulnerability of fish species (the index values ranging from 1 to 100, with 100 being the most vulnerable) was calculated based on the species life history and ecological characteristics. The input variables consisted of traits that were considered to be related to the species intrinsic vulnerability and were obtained from literature review (Cheung et al. 2005). These traits included maximum length, age at first maturity, longevity, von Bertalanffy growth parameter $(K)$, natural mortality, fecundity (only low fecundity is considered), spatial behaviour and geographic range. In brief, the expert system classified fish species into different life history categories with different degrees of membership or association (e.g. 'large' maximum length, 'moderate' age at maturity). The degree of membership of, or association to, each category ranged from 0 to 1 ( 0 - no association, 1 -full association) and was determined by pre-defined fuzzy logic membership functions (Cheung et al. 2005). The expert system was flexible in terms of data availability, and the minimum required input was the maximum length. Linguistic rules expressed as IF (predicate)-THEN (conclusion) clauses were used to infer the levels of species intrinsic vulnerability. An example of a linguistic rule is: IF maximum length is large THEN intrinsic vulnerability is high.

The rules were developed from published literature and expert opinions (Cheung et al. 2005). The degrees of membership of different conclusions (the level of intrinsic vulnerability) were based on the membership of the predicates and were accumulated by the expert system through:

Membership $_{e}=$

Membership $_{e-1}+$ Membership $_{i} \times\left(1-\right.$ Membership $\left._{e-1}\right)$

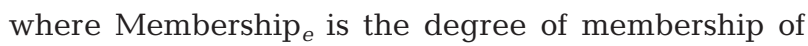
the conclusion after combining the conclusions from $e$ pieces of rules, and Membership $p_{i}$ is the degree of membership of the conclusion of rule $i$. An index of intrinsic vulnerability was calculated from the index values at the peak (maximum membership) of each 'conclusion' fuzzy membership function weighted by the degrees of membership to each conclusion category.
The intrinsic vulnerability index predicted from the fuzzy logic expert system had been validated through comparisons with empirical data and sensitivity analysis (Cheung et al. 2005). The predicted index value was significantly correlated with empirically observed rate of population declines from a wide range of datasets. Moreover, sensitivity analysis of model parameters and structures showed that the predictions from the expert system were robust to the major assumptions (Cheung et al. 2005).

Intrinsic vulnerability index of marine fishes. A list of the world marine fish species ( $\mathrm{n}=15723$ ) was obtained from FishBase (Froese \& Pauly 2004). Values for the species life history and ecological characteristics were obtained from published literature, notably those that were recorded in FishBase. To reduce the uncertainty of the predicted vulnerability index value, species in which total length was the only available life history parameter were excluded. As a result, the number of species included in the analysis was reduced to 1353 .

Marine fishes in the analysis were categorized according to their association to the 4 major habitats where fishes may have evolved different sets of life history traits and received different characteristics of threats. The habitat categories are: (1) coral reefassociated, (2) estuarine, (3) seamount, and (4) seamount-aggregating fishes. The lists of coral reef and estuarine species were based on information recorded in FishBase. Seamount fishes are defined as fishes that have been recorded on seamounts, while those seamont fishes that aggregate in association with seamounts and similar topographic bathymetric features were categorized as seamount-aggregating fishes (Koslow 1997, Morato et al. 2006a). Seamount and seamount aggregating fish species were based on the list published by Morato et al. (2006a). The average predicted intrinsic vulnerability indices of fishes associated to the 4 habitats were compared using the TukeyKramer HSD test.

Fish species were also categorized according to their depth range, latitudinal range, and position in the water column. These attributes were considered to be related to the fishes' life history (Macpherson \& Duarte 1994, Gaston \& Blackburn 2000). In general, marine fishes inhabiting deeper environments, with a larger latitudinal range or wider geographic range tend to have larger maximum body size (Macpherson \& Duarte 1991, 1994). These traits (maximum body size, in particular) may then affect the intrinsic vulnerability of fishes to fishing. Depth and latitude were represented by the median of the species depth and latitude range and the range sizes; while position in water column was categorized as: (1) demersal, (2) pelagic, (3) benthopelagic, (4) bathypelagic or (5) bathydemersal. 
Median depth ranges were log-transformed to correct for the non-linear relationship between depth and intrinsic vulnerability. Information on these attributes was taken from FishBase.

Relationships between the environmental attributes (depth, latitude and habitats) and the index of intrinsic vulnerability of fish species $(V)$ were evaluated using a generalized linear model (GLM) (Kutner et al. 2005). To test the effects of each of the factors that may correlate with the intrinsic vulnerability, the full GLM model was structured as:

$$
\begin{aligned}
V= & \alpha+\beta_{\text {Lat }} \times \text { Lat }+\beta_{\text {LatRange }} \times \text { LatRange }+\beta_{\text {Depth }} \times \log (\text { Depth }) \\
& +\sum_{i=1}^{5} \beta_{P, i} \times P_{i}+\sum_{j=1}^{4} \beta_{\text {Habitat }, j} \times \text { Habitat }_{j}+\varepsilon
\end{aligned}
$$

where $\alpha$ is the average intrinsic vulnerability of all marine fishes; Lat is the median value of the latitudinal range; LatRange is the latitudinal range; Depth is median of the depth range; and $P$ and Habitat are categorical factors representing the positions in water column $i$ and habitat types $j$, respectively. $\beta_{\text {LatRange }}$ $\beta_{\text {Depth }} \beta_{P, i}$ and $\beta_{\text {Habitat }, j}$ are the coefficients of the factors: latitudinal range, median of depth range, position $i$ in water column and habitat type $j$, respectively. $\varepsilon$ is the error term. The significance of the factors was evaluated with $t$-tests.

As geographic range (closely correlated with latitudinal range) is an attribute in the expert system, it might appear that the dependency of the intrinsic vulnerability index $(V)$ on the latitudinal ranges of the fishes would invalidate the GLM. However, geographic range is positively correlated with maximum body length (Macpherson \& Duarte 1994). The rules in the expert system stipulated that geographic range and maximum length contribute to intrinsic vulnerability in an opposite way, i.e. vulnerability increases with maximum body size but decreases with distribution range. Here, the GLM explored how such covariation affects the intrinsic vulnerability of fishes to fishing in different environments (e.g. depth and latitude).

Mean intrinsic vulnerability index of catch. Catches of the world from 1950 to 2003 were obtained from the Sea Around Us Project global catch database (www.seaaroundus.org). The Sea Around Us Project catch database was constructed from catch or landing statistics from around the world, notably the fisheries statistics of the United Nations Food and Agriculture Organization (FAO). Based on predicted geographic distributions of exploited taxa and a rule-based model, the original catch data were disaggregated spatially (by 30 min latitude $\times 30$ min longitude cells covering the world's oceans) and taxonomically (Watson et al. 2004).

We classified the exploited fish taxa reported in the catch database (858 taxa) by their associated habitat. In the Sea Around Us Project catch database, each ex- ploited taxon (reported as species or as a taxonomically aggregated group by family or genus) was given a 'habitat affinity'. The habitat affinity represents the frequency of occurrence or the relative density of a taxon in a particular habitat (coral reef, estuary, seamount and other habitats; Table 1) and is expressed as an index ranging from 0 to 1 ( 0 - no affinity; 1 - maximum affinity; Table 2). From published literature, databases (e.g. FishBase), and/or through personal communications from experts, we collated qualitative descriptions on each taxon's abundance, density or commonness in each habitat (Table 2). Based on the collated information, each taxon was assigned an affinity index value to each habitat. A taxon may be associated with multiple habitats. For instance, striped bass Morone saxatilis was described as 'prefers estuaries' but it also occurs in 'other habitats' (Table 1); thus, it received an index value of 0.75 for estuaries and 0.5 for 'other habitats'. This was repeated for all exploited taxa in the Sea Around Us Project global catch database. If specific habitat association information for a taxon aggregated at a higher taxonomic level (e.g. Genera, Family) was not available, their index values were approximated from the average index values of their composite taxa at a lower taxonomic level (e.g. species). These values had been used to allocate reported annual catches from fisheries statistics to different areas of the world oceans (Close et al. 2006). The assigned habitat affinity values are available online (www.searoundus.org).

Table 1. Habitat categories assigned to each taxon, with some of the terms typically associated with them (from FishBase and other sources). Global distribution maps of these habitats are available from the Sea Around Us Project

\begin{tabular}{|ll|}
\hline Category & \multicolumn{1}{c|}{ Term } \\
\hline Estuary & Estuaries, mangroves, river mouth \\
Coral & Coral reef, coral, atoll, reef slope \\
Seamounts & Seamounts \\
Other habitats & Muddy/sandy/rocky bottom \\
\hline
\end{tabular}

Table 2. Commonly-used descriptions for the relative association of a taxon to its habitat category (Table 1) and its assigned affinity index. The affinity index for 'Other habitats' is assumed to be 0.1 when no information on habitat association is available

\begin{tabular}{|lc|}
\hline Description & Affinity index \\
\hline Absent or rare & 0 \\
Occasionally, sometimes & 0.25 \\
Often, regularly, seasonally & 0.5 \\
Usually, abundant in, prefers & 0.75 \\
Always, mostly, only occurs & 1 \\
aIf a taxon occurs in a habitat but no description of the & \\
strength of the association is found, we assumed a default \\
score of 0.5
\end{tabular}


The average intrinsic vulnerability index of fishes in the catch (hereafter called 'average vulnerability of catch') over the past 5 decades was calculated from the arithmetic mean of the intrinsic vulnerability index of fish taxa weighted by their annual catch. Annual catches by taxon from 1950 to 2003 that had been disaggregated into a world ocean map (represented by 30 min latitude $\times 30$ min longitude cells) were obtained from the Sea Around Us Project database. Time-series of average vulnerability of catch for all the 858 fish taxa with non-zero affinity to coral reef, estuary and seamount-associations were calculated separately. We overlaid global maps of coral reefs (UNEP World Conservation Monitoring Centre, Cambridge, UK), estuaries (Alder 2003) and seamounts (Kitchingman \& Lai 2004) onto the spatial catch data. For each habitat and exploited taxon, we calculated the annual catch from areas where the particular habitat occurred. Catches were considered to originate from a particular habitat if: (1) the catches came from taxa that are associated with that habitat, and (2) the catches came from areas where that particular habitat existed. The intrinsic vulnerability index for each of the 858 taxa was predicted using the fuzzy logic expert system (see Appendix 1 in MEPS Supplementary Material at www.int-res.com/articles/suppl/ m333p001_app.pdf). Using these data, the average vulnerability of catch by habitat over the past 5 decades was calculated. To understand the changes in community structure that led to any observed trends in average vulnerability of catch, surface-plots of intrinsic vulnerability and total catch of fishes against time were created.

Comparison with distributions of globally threatened fishes. Marine fishes that were listed under the IUCN Red List of Threatened Species (Baillie et al. 2004) were mapped onto the 30 min latitude $\times 30$ min longitude cells. These included 161 species of fishes that are listed under the vulnerable, endangered and critically endangered categories. Distributions of species were obtained from published literature, maps, and reports. For species without published distribution maps, their distributions were predicted using a rulebased model based on information such as depth range, latitudinal range and occurring ocean basins (see Watson et al. 2004 and www.seaaroundus.org for details). The number of red-listed species and the time-series of average vulnerability of catch of demersal fishes in each cell was estimated. For each cell in the world ocean map, the slope of the changes in average vulnerability of catch between 1950 and 2003 were estimated using linear regression. Slopes with negative values indicate declines in average vulnerability of catch and otherwise for those with positive values. Correlations between the Red List species number and the slope of time-series average vulnerability of catch in each grid were then tested using the Kendall corre- lation test (Kutner et al. 2005). Although the choice of fishes that had been assessed by the Red List was biased (e.g. species that were known to be more vulnerable were more likely to be assessed), the IUCN Red List represented one of the most authoritative global list of threatened marine fishes. It should be useful in revealing large-scale general qualitative patterns. The validity of using the IUCN Red List in this analysis is further elaborated in the discussion section.

\section{RESULTS}

\section{Intrinsic vulnerability of fish with different associated habitats}

The estimated indices of intrinsic vulnerability of marine fish species varied between habitats (Fig. 1, Table 3). The average intrinsic vulnerability index of coral reef-associated and estuarine fishes (43.3 \pm 1.2 SE and 45.3 \pm 1.0 SE, respectively) had similar level of intrinsic vulnerability (Tukey-Kramer HSD test, $\mathrm{p}>$ 0.05). However, coral reef fishes were slightly less vulnerable than all analyzed marine fishes (TukeyKramer HSD test, $\mathrm{p}<0.05)$. The predicted intrinsic vulnerabilities of seamount and seamount-aggregating fishes were significantly higher than coral reef and estuarine fishes (Table 3) (Tukey-Kramer HSD test, $\mathrm{p}<0.05$ ). Particularly, seamount-aggregating fish, a sub-set of seamount fishes, had the highest average intrinsic vulnerability index value among all groups (63.9 \pm 3.1 SE), and was similar to fishes that were listed under the IUCN Red List of Threatened Species (Fig. 1).

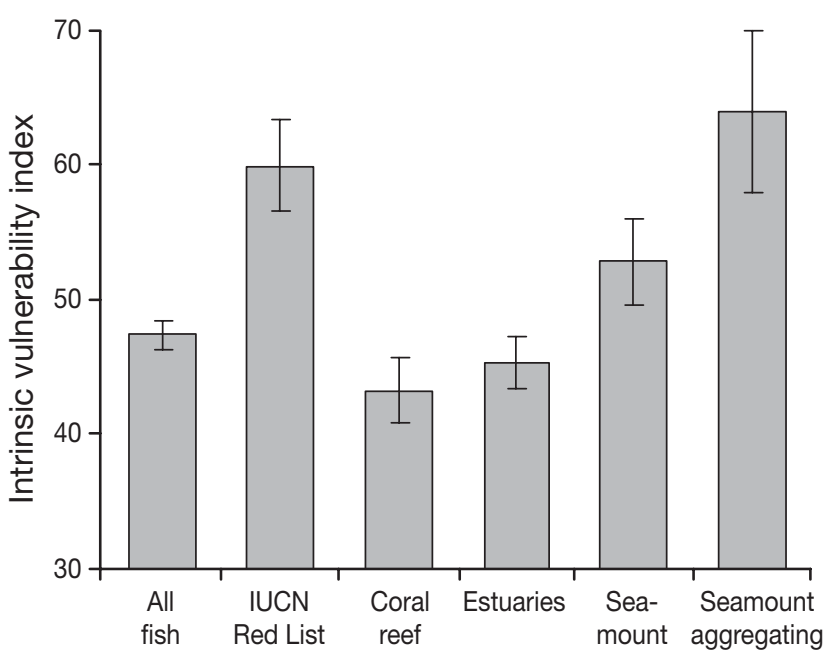

Fig. 1. Mean intrinsic vulnerability index of marine fish that are categorized as: all fish species $(\mathrm{N}=1353)$; species listed under the IUCN Red List $(\mathrm{N}=161)$; coral reef-associated species ( $\mathrm{N}=243)$, estuaries-associated species $(\mathrm{N}=381)$, seamount aggregating species (172), seamount-aggregating species $(\mathrm{N}=15)$. Error bars $=95 \%$ confidence limits 
Table 3. Comparisons of the intrinsic vulnerability between fishes associated with different habitats. The values represent the difference between the mean intrinsic vulnerability index of the communities associated to the habitats listed on the first column and the first row. ${ }^{*}$ Indicates that the intrinsic vulnerabilities of the pair of fish communities are significantly different from each other at the $\mathrm{p}<0.05$ confidence level in the Tukey-Kramer HSD test $(q=2.574)$

\begin{tabular}{|lcccccc|}
\hline & $\begin{array}{c}\text { All marine } \\
\text { fishes }\end{array}$ & $\begin{array}{c}\text { Coral } \\
\text { reef }\end{array}$ & Estuarine & $\begin{array}{c}\text { Sea- } \\
\text { mount }\end{array}$ & $\begin{array}{c}\text { Seamount- } \\
\text { aggregating }\end{array}$ \\
\hline All marine fishes & & $4.1^{*}$ & 2.04 & $-5.44^{*}$ & $-16.56^{*}$ \\
Coral reef & $-4.1^{*}$ & & -2.06 & $-9.54^{*}$ & $-20.67^{*}$ \\
Estuarine & -2.04 & 2.06 & & $-7.41^{*}$ & $-18.61^{*}$ \\
Seamount & $5.44^{*}$ & $9.54^{*}$ & $7.47^{*}$ & & -11.13 \\
Seamount-aggregating & $16.56^{*}$ & $20.67^{*}$ & $18.61^{*}$ & -11.13 & \\
\hline
\end{tabular}

seamounts (Fig. 2c-f). The decline was stronger for coral reef-associated fishes (Fig. 2c), from a mean average vulnerability of catch of 50 (out of 100) in 1950, to 40 in the 2000s. Estuarine fishes also showed a consistent decline (Fig. 2d). When all exploited seamount fishes were considered, average vulnerability of catches fluctuated widely over the past 5 decades (Fig. 2e). The fluctuations, however, were mainly attributed to the high catch of small pelagic fish. When small pelagic fishes were excluded from the analysis, average vulnerability of catch for seamount fishes

The intrinsic vulnerability index values were significantly related to positions in water column, depth and latitudinal ranges (Table 4). Fishes occupying the bathypelagic region (i.e. the oceanic zone between 1000 to $4000 \mathrm{~m}$ deep) showed significantly lower vulnerability. When position in the water column was the only independent factor considered, bathydemersal fishes had the highest vulnerability index, followed by benthopelagic, then demersal and pelagic fishes. The significance of the position in the water column (except for bathypelagic and bathydemersal fishes) was lost when latitudinal and bathymetric variables were added. The occurrence depth (represented by the log-transformed median of the species' depth range) and latitudinal range was positively and significantly related to the species' vulnerability index. When position in the water column, depth and latitudinal factors were accounted for, habitat type was only marginally significant in explaining the variations in the vulnerability index. Coral reef-associated, seamount-associated and estuarine fishes did not have significantly different indices, while seamount-aggregating fishes were significantly $(p<0.05)$ more vulnerable.

\section{Average intrinsic vulnerability index of catch}

The average vulnerability of catches of marine fishes declined from 1950 to 2003 (Fig. 2). The trends were similar whether all exploited fishes or only coastal fishes were considered (Fig. 2a). The large fall and rise of average vulnerability of catch mainly resulted from the large catches of Peruvian anchovy (with low vulnerability) and the collapse of the anchovy in the 1970s and 1980s. When small pelagic fishes were excluded from the analysis, the average vulnerability of catch declined more smoothly (Fig. 2b).

The average vulnerability of catches from coral reefs and estuaries declined, while the trend was less clear for increased consistently from the 1970 s to the late 1990s, and appeared to be levelling off since 2000 (Fig. 2f).

The declines in average vulnerability of catches generally resulted from the slight decrease in catches of more vulnerable species and the increase in catches of low vulnerability species (Fig. 3). Catches of fishes with intrinsic vulnerability indices of around 60 increased from the 1950s, peaked in the 1990s and appeared to be declining since then (Fig. 3a). At the same time, catches of fishes with low vulnerability (vulnerability indices below 60) continued to increase rapidly. When we only included catches of demersal fishes from coastal areas (defined here as less than $50 \mathrm{~m}$ deep or within $100 \mathrm{~km}$ from the nearest coast), such trends became clearer (Fig. 3b,c). In the offshore areas (the complement of coastal areas), highly vulnerable fish catches peaked in the 1980s. On the other hand, the pattern of increasing catches of low vulnerability fishes is less clear. Catches of very high vulnerability fishes (vulnerability index $=70$ to 90 ) were small in volume and showed an increase since the late 1980s (Fig. 3b,d).

Table 4. Results of the generalized linear model for the relationships between the range attributes (depth, latitude and position in water column) and the index of intrinsic vulnerability of 1514 marine fish species. ${ }^{* *} p<0.01$

\begin{tabular}{|lcccc|}
\hline Factors & Coefficients & $\mathrm{SE}$ & $t$ & $\mathrm{p}$ \\
\hline Intercept & 20.47 & 2.89 & 7.074 & $<0.001^{* *}$ \\
Pelagic & 0.31 & 2.10 & 0.149 & 0.882 \\
Demersal & 0.69 & 1.06 & 0.653 & 0.514 \\
Benthopelagic & 4.62 & 2.41 & 1.912 & 0.056 \\
Bathypelagic & -28.46 & 3.11 & -9.168 & $<0.001^{* *}$ \\
Bathydemersal & 6.64 & 2.39 & 2.775 & $0.006^{* *}$ \\
log(median depth) & 4.94 & 0.46 & 10.765 & $<0.001^{* *}$ \\
Latitudinal range & 0.07 & 0.02 & 4.134 & $<0.001^{* *}$ \\
Coral reef-associated & -0.84 & 1.80 & -0.467 & 0.641 \\
Estuarine & 2.36 & 1.79 & 1.315 & 0.189 \\
Seamount & -0.23 & 2.25 & -0.102 & 0.919 \\
Seamount-aggregating & 10.85 & 3.75 & 2.893 & $0.004^{* *}$ \\
\hline
\end{tabular}



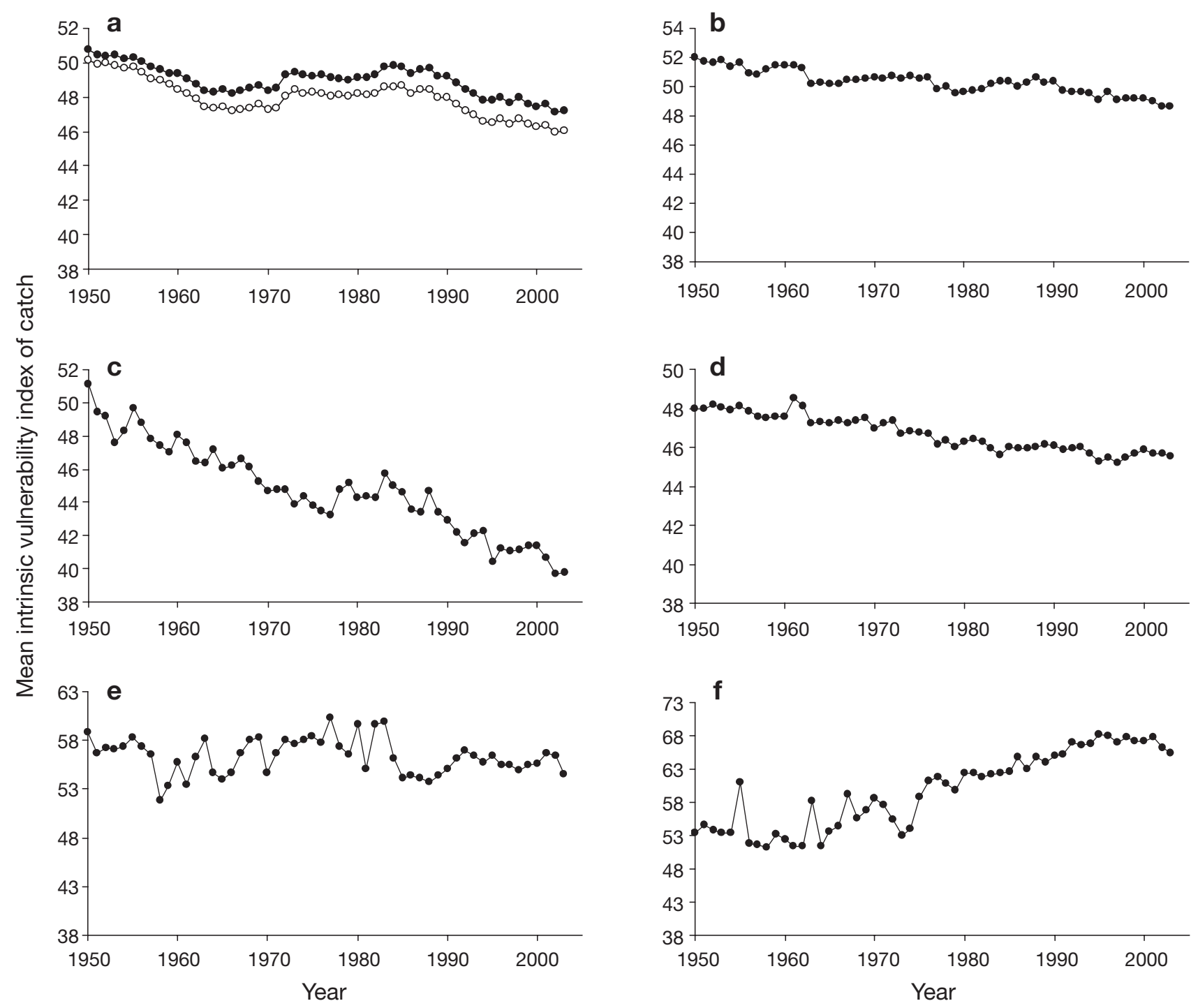

Fig. 2. Average intrinsic vulnerability index weighted each year by the annual catch of: (a) all exploited fish species (•) and all coastal exploited fish species (O); (b) all exploited fish species except small pelagic fishes; (c) coral reef-associated fish species; (d) estuarine fish species; (e) seamount fish species; (f) seamount fish species (except small pelagics). The average intrinsic vulnerability of the catch ranges from 1 to 100. A higher value represents greater vulnerability

\section{Comparing average vulnerability of catch and number of red-listed fishes}

The map of the global distribution of the number of marine fishes in the IUCN Red List showed that high concentrations of red-listed fishes mainly occur along the continental shelf (Fig. 4). In the world ocean map, where the number of red-listed fishes in each $30 \mathrm{~min}$ latitude $\times 30$ min longitude cell was calculated, cells within the highest quartile of the number of red-listed species were all found along the continental shelf. In terms of ocean basins, high concentration of red-listed fishes was observed in the Indo-Pacific, Northwest Pacific and Northwest and East-Central Atlantic (particularly the Caribbean).
The distribution of red-listed marine fishes agrees with the spatial patterns of changes in the average vulnerability of catch. In the world ocean map, most 30 min latitude $\times 30$ min longitude cells in inshore and continental shelf waters showed declines in average vulnerability of catch from 1950 to 2003. These were also the areas where the bulk of fishes were being caught. The slopes were mostly positive or very small $( \pm 0.01)$ in the cells representing the high seas (i.e. areas outside the Exclusive Economic Zones or any national jurisdiction), indicating a slight increase or no change in average vulnerability of catch over the past 5 decades. Cells with negative slope concentrated more in the Indo-Pacific, Northwest Pacific, North Atlantic and the Caribbean. Kendall correlation tests 

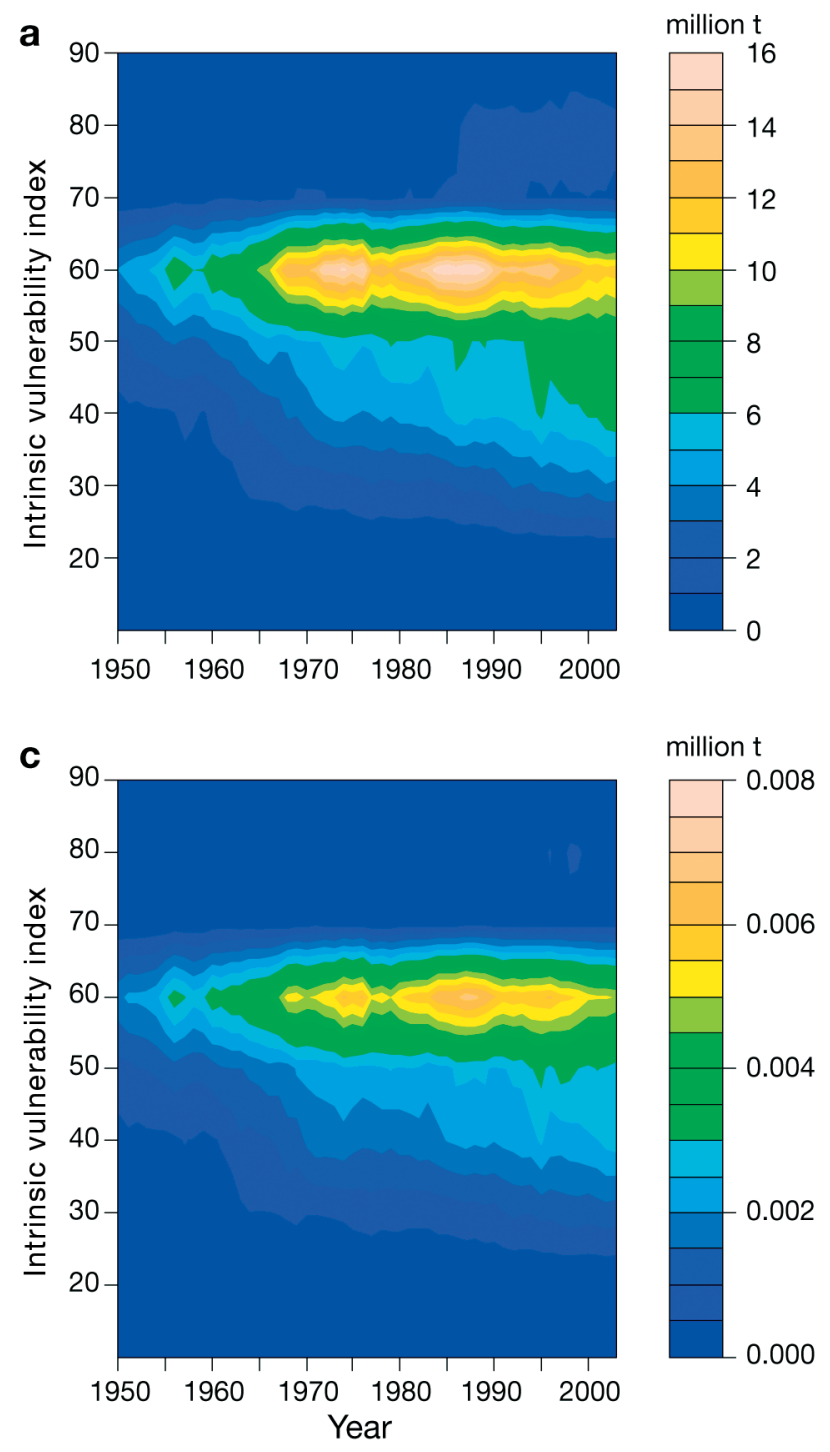

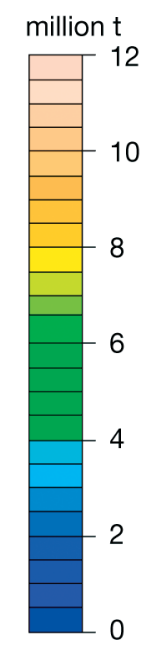

d

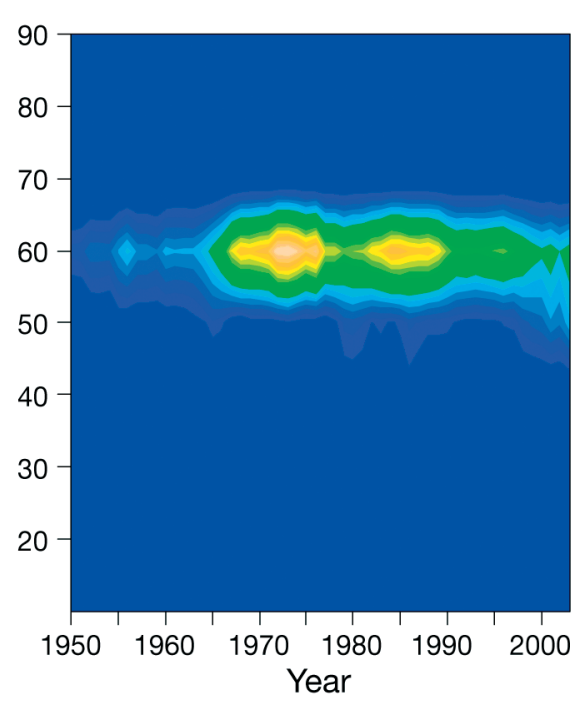

million $\mathrm{t}$

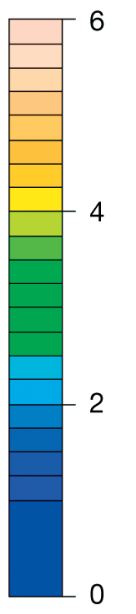

Fig. 3. Surface plot of catch of fish species with different intrinsic vulnerability indices from 1950 to 2003 of (a) all exploited fish species; (b) coastal exploited fish species; (c) coastal demersal fish species; (d) offshore demersal fish species

showed that the slopes of average vulnerability of catch and number of fishes listed under the IUCN Red List were significantly and negatively correlated $(\mathrm{p}<0.01)$. This means that more threatened fishes occur in areas where average vulnerability of catch (of demersal fishes) declined from the 1950s to the 2000s.

\section{DISCUSSION}

\section{Intrinsic vulnerability of fish with different associated habitats}

This study supports the proposed hypothesis that fish communities differ in intrinsic vulnerabilities as a result of different life histories and ecology. Particu- larly, the findings agreed with previous conclusions that seamount-aggregating fishes are extremely vulnerable (Koslow 1996, 1997, Morato et al. 2006a). Seamount fish communities consist of demersal and benthopelagic species inhabiting deeper waters. Deepwater demersal fishes, represented here as bathydemersal, are highly vulnerable because of their larger sizes, slower growth and later maturity (Koslow 1996, 1997). Such life history patterns allow them to adapt to the deepwater environment (Koslow 1996). Deepwater pelagic (mesopelagic and bathypelagic) fishes are generally small-sized and fast-growing (Childress et al. 1980), and thus have lower intrinsic vulnerability (Rex \& Etter 1998). Examples of deepwater demersal and benthopelagic species associated with seamounts include orange roughy Hoplostethus atlanticus, deep- 


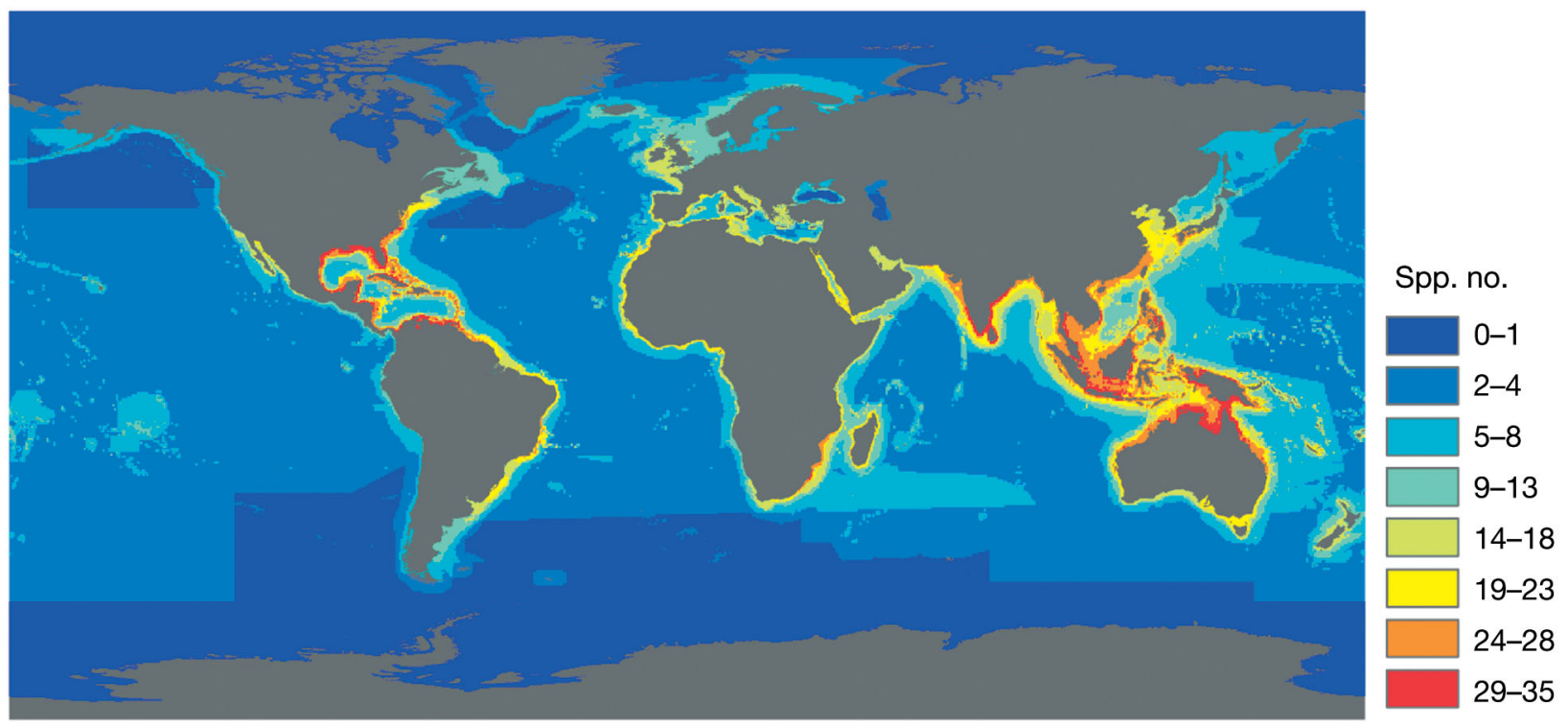

Fig. 4. Number of marine fish species listed in the IUCN Red List of Threatened Species (Baillie et al. 2004) in a 30 min latitude $\times 30$ min longitude grid

water oreos (Family: Oreosomatidae) and rockfish (Sebastes spp.). Besides their vulnerable life history patterns (Koslow 1996, 1997), these fishes have a high tendency to form aggregations around seamounts which renders them even more vulnerable to exploitation. Although the coral reef communities appeared to have a low average vulnerability index to fishing, this can be attributed to the large diversity of small-bodied species that are evolved to utilize the many niches provided by the complex coral reef structure (Sale 1977). On the other hand, high species diversity in coral reef communities also means that the absolute number of fish with vulnerable life histories may be considerable. Estuarine fish communities consisted of a mixture of freshwater and marine migrants and residents (Blaber 2000). Thus the community structures are relatively more transient. This may explain the similarity in average intrinsic vulnerability between estuarine fishes and all marine fishes.

\section{Intrinsic vulnerability and geographic range}

The significant positive relationship between latitudinal range and the vulnerability index suggests that fish species with a large geographic range may be more vulnerable to fishing. Macroecological theory predicts that geographic range (approximated here by latitudinal range) is positively related to maximum body size, as large-bodied animals tend to be generalists, have higher mobility and need more resources, which explains their larger range size (Gaston \& Black- burn 2000). As body size is positively correlated with intrinsic vulnerability (Dulvy et al. 2003, Reynolds et al. 2005a), vulnerability and latitudinal range are thus correlated. This relationship implies that wide ranging fishes may be more vulnerable to fishing - which contradicts previous conclusions that fishes with large geographic ranges should be less vulnerable. Geographic range was an attribute used to calculate the vulnerability index. However, the 'rule' in the model specified that species with small geographic range should have high vulnerability (Cheung et al. 2005). Thus the positive geographic range and vulnerability relationship obtained from the results should not be an artifact of the model.

\section{Average intrinsic vulnerability of catch}

The results from this study support the hypothesis that global fisheries catches were increasingly dominated by less intrinsically vulnerable fish species while intrinsically vulnerable fishes became over-exploited or depleted. The consistent declines of average vulnerability of catch of exploited fishes were generally caused by the reduced catches of more vulnerable species, while catches of less vulnerable species increased. This trend was particularly prominent in coastal regions.

The findings agreed well with life history theory and the empirical evidence of serial depletion from more vulnerable to less vulnerable species worldwide. Firstly, large declines in abundance of animals in coastal and estuarine ecosystems had been estimated from histori- 
cal ecosystem reconstructions (Lotze et al. 2006). Secondly, empirical evidence at regional scale shows significant relationships between intrinsic vulnerability and changes in community structure because of fishing (Jennings et al. 1998, Cheung et al. 2005). Also, in general, life history theory predicts that abundances of intrinsically more vulnerable fishes decline faster than those of less vulnerable fishes (Jennings et al. 1998, 1999a). In fact, the majority of the currently overexploited, depleted or collapsed fishery stocks are large demersal fishes (Hutchings 2000). In this study, these species were shown to have high vulnerability. Moreover, the large-scale depletion of predatory fishes (Baum et al. 2003, Christensen et al. 2003) and numerous accounts of local extinction of highly vulnerable species (Casey \& Myers 1998, Dulvy et al. 2003, Sadovy \& Cheung 2003) support the hypothesis that the decline in average vulnerability of catch was largely a result of over-exploitation of the more vulnerable fishes. Although catches of extremely highly vulnerable species (intrinsic vulnerability index $\geq 70$ ) also increased recently, particularly those from offshore waters, their contributions to the global catches were relatively small. Current evidence suggests that the increasing exploitation of the offshore deepwater stocks that generally have vulnerable life histories is not sustainable (Morato et al. 2006b). The apparent increase in catch was sustained by serial depletions of previously unexploited and inaccessible stocks.

The likelihood of alternative explanations for the observed changes in average vulnerability of catches that were independent of exploited stock status was relatively small. These alternative explanations include changes in market demand and accessibility to fishing grounds. However, a large scale shift in market demand for smaller or less vulnerable fishes independent of the exploited stock status was not apparent in the past 5 decades. Moreover, changes in accessibility to fishing grounds would have affected the catches of fishes across the spectrum of intrinsic vulnerability similarly. On the other hand, the consistent patterns observed in the different habitats and the supporting evidence from empirical studies suggest that the changes in average vulnerability of catch should be contributed mainly to changes in fish community structure.

The steep decline in average vulnerability of coral reef fish catch over the last 5 decades indicated that the more vulnerable reef fishes might have been depleted rapidly. Catches of intrinsically vulnerable reef fishes such as groupers (Serranidae) declined, while those from less vulnerable fishes such as rabbitfishes (Siganidae), goatfishes (Mullidae) and bigeyes (Priacanthidae) increased greatly. As the coral reef fish community is relatively more stable compared to other communities such as estuarine, changes in composition of coral reef fishes resulting from serial depletion of fishes with different vulnerabilities can be detected more easily. On the contrary, the high volatility of estuarine communities may partly explain their weaker decline in average vulnerability of catch.

This study shows that high concentrations of threatened fishes occur in the Indo-Pacific and the Caribbean, where coral reefs are extensive (Spalding et al. 2004). Together with other direct and indirect threats such as destructive fishing, geographic expansions of the live reef fish trade, coastal development, and climate change (Pandolfi et al. 2003, Sadovy 2005), coral reef habitat should warrant high conservation attention.

The increasing exploitation of deepwater (Morato et al. 2006b) and seamount fishery resources is of concern (Koslow 1997, Koslow et al. 2000, Morato et al. 2006a). Seamount communities are generally more vulnerable to fishing. Also, fisheries on seamounts are often 'boom-and-bust', i.e. rapidly over-exploit a seamount soon after its discovery, then moving on to the next to be discovered, resulting in serial depletion of seamount populations. This might explain the increase in catches of highly vulnerable offshore fishes and the consistent increase in average vulnerability of catch in seamounts. Moreover, the high vulnerability of the seamount communities means that the populations may be over-exploited rapidly once fishing develops, before a management plan and regulations are in place. The sustainability of such fisheries is in doubt (Clark 2001).

The positive spatial correlation between the number of fish species listed under the IUCN Red List and the rate of decline of average vulnerability of catch provided further support for the over-exploitation of more vulnerable stocks. Although fishes that were selected for assessment by the IUCN Red List might have been biased towards the more vulnerable species, this also means that the distribution of the red-listed species reflects the area where intrinsically more vulnerable and currently endangered species were concentrated. Thus the broad-scale patterns of distribution of the red-listed fishes should be useful in revealing general patterns of threatened species distributions.

The general conclusion of this analysis should be robust to the varying quality of the original catch data between fisheries and countries. The taxonomic and spatial resolutions of the original data (mainly from FAO) are poor in some regions of the world. This may have limited the sensitivity of our method to detect changes in average vulnerability of catch (Pauly \& Palomares 2005). For example, a mixture of species might have been reported in a single group. These species may have different intrinsic vulnerabilities. As 
they are aggregated within a single group, their serial depletion would not be detected by the analysis in this study. Also, it is difficult to reveal spatial serial depletion of different populations (e.g. fishing shifts further offshore as inshore stocks are depleted) from landings data reported at country or regional level. Thus we believe that the uncertainty of the data quality can result in underestimation of the decline in the average intrinsic vulnerable of catch over time (Pauly \& Palomares 2005).

This study demonstrated the large-scale effects of fishing on structures of fish communities that are related to their intrinsic vulnerability to fishing. Although seamount communities showed distinctively higher vulnerability, the nature of threats from fishing shared many similarities with coral reef fishes. This study suggested that the coral reef communities in the IndoPacific and the Caribbean, the deepwater demersal fishes and the seamount-aggregating fishes worldwide are particularly threatened by fishing. If present trends persist, it is likely that the more vulnerable species will suffer considerable risk of severe population depletion, extirpation or extinction (Cheung et al. in press). More comprehensive understanding of the levels of threat to marine species from fishing can be attained by extending the IUCN assessment to all exploited marine fishes.

Acknowledgements. We are grateful to A. Kitchingman, C. Close and F. Valdez for their help in GIS analyses and data mining. We thank the 3 anonymous referees for comments on the manuscript. W.W.L.C was supported by the Sir Robert Black Trust Fund and a University of British Columbia Graduate Fellowship during this study. T.M. acknowledges support from the Fundação para a Ciência e Tecnologia (Portugal, BD4773/2001) and the European Social Fund through the Third Framework Programme. We also acknowledge funding support from the Canadian National Scientific and Engineering Research Council and the Pew Charitable Trusts through the Sea Around Us Project.

\section{LITERATURE CITED}

Alder J (2003) Putting the coast in the Sea Around Us Project. Sea Around Us Newsl 15:1-12

Baillie JEM, Hilton-Taylor C, Stuart SN (eds) (2004) 2004 IUCN red list of threatened species: a global species assessment. IUCN The World Conservation Union, Gland

Baum JK, Myers RA, Kehler DG, Worm B, Harley SJ, Doherty PA (2003) Collapse and conservation of shark populations in the Northwest Atlantic. Science 299:389-392

Begon M, Townsend C, Harper JL (2005) Ecology: from individuals to ecosystems. Blackwell Scientific, Oxford

Blaber SJM (2000) Tropical estuarine fishes: ecology, exploitation, and conservation. Blackwell Science, Oxford

Casey JM, Myers RA (1998) Near extinction of a large, widely distributed fish. Science 281:690-692

Charnov E (1993) Life history invariants. Oxford University Press, New York

Cheung WWL, Pitcher TJ, Pauly D (2005) A fuzzy logic expert system to estimate intrinsic extinction vulnerability of marine fishes to fishing. Biol Conserv 124:97-111

Cheung WWL, Pitcher TJ, Pauly D (in press) Using an expert system to evaluate vulnerabilities and conservation risk of marine fishes from fishing. In: Lipshitz AP (ed) New research on expert system. Nova Science Publishers, New York

Childress JJ, Taylor SM, Cailliet GM, Price MH (1980) Patterns of growth, energy utilization and reproduction in some meso- and bathypelagic fishes off Southern California. Mar Biol 61:27-40

Christensen V, Guénette S, Heymans JJ, Walters C, Watson R, Zeller D, Pauly D (2003) Hundred-year decline of North Atlantic predatory fishes. Fish Fish 4:1467-2979

Clark M (2001) Are deepwater fisheries sustainable? The example of orange roughy (Hoplostethus atlanticus) in New Zealand. Fish Res 51:123-135

Close C, Cheung WWL, Hodgson S, Lam V, Watson R, Pauly D (2006) Distribution ranges of commercial fishes and invertebrates. In: Palomares MLD, Stergiou KI, Pauly D (eds) Fishes in databases and ecosystems. Fish Cen Res Rep Univ Vancouver 14:27-37

Dulvy NK, Sadovy Y, Reynolds JD (2003) Extinction vulnerability in marine populations. Fish Fish 4:25-64

Essington TE, Beaudreau AH, Wiedenmann J (2006) Fishing through marine food webs. Proc Natl Acad Sci 103: 3171-3175

Froese R, Pauly D (2004) FishBase. Available at: www.fishbase.org

Gaston KJ, Blackburn TM (2000) Pattern and process in macroecology. Blackwell Science, London

Goodwin NB, Grant A, Perry AL, Dulvy NK, Reynolds JD (2006) Life history correlates of density-dependent recruitment in marine fishes. Can J Fish Aquat Sci 63:494-509

Hutchings JA (2000) Collapse and recovery of marine fishes. Nature 406:882-885

Jennings S, Reynolds JD, Mills SC (1998) Life history correlates of responses to fisheries exploitation. Proc R Soc Ser B 265:333-339

Jennings S, Greenstreet SPR, Reynolds JD (1999a) Structural change in an exploited fish community: a consequence of differential fishing effects on species with contrasting life histories. J Anim Ecol 68:617-627

Jennings S, Reynolds JD, Polunin NVC (1999b) Predicting the vulnerability of tropical reef fishes to exploitation with phylogenies and life histories. Conserv Biol 13:1466-1475

Kitchingman A, Lai S (2004) Inferences of potential seamount locations from mid-resolution bathymetric data. In: Morato T, Pauly D (eds) Seamounts: biodiversity and fisheries. Fish Cen Res Rep Univ Vancouver 12(5):7-12

Koslow JA (1996) Energetic and life history patterns of deepsea benthic, benthopelagic and seamount-associated fish. J Fish Biol 49A:54-74

Koslow JA (1997) Seamounts and the ecology of deep-sea fisheries. American Scientist 85:168-176

Koslow JA, Boehlert GW, Gordon DM, Haedrich RL, Lorance P, Parin N (2000) Continental slope and deep-sea fisheries: implications for a fragile ecosystem. ICES J Mar Sci 57: 548-557

Kutner MH, Nachtsheim CJ, Neter J, Li W (2005) Applied linear statistical models. McGraw-Hill, New York

Lotze HK, Lenihan HS, Bourque BJ, Bradbury RH and 6 others (2006) Depletion, degradation, and recovery potential of estuaries and coastal seas. Science 312:1806-1809

Macpherson E, Duarte CM (1991) Bathymetric trends in demersal fish size-is there a general relationship? Mar Ecol Prog Ser 71:103-112 
Macpherson E, Duarte CM (1994) Patterns in species richness, size, and latitudinal range of East Atlantic fishes. Ecography 17:242-248

Morato T, Cheung WWL, Pitcher TJ (2006a) Vulnerability of seamount fish to fishing: fuzzy analysis of life-history attributes. J Fish Biol 67:1-13

Morato T, Watson R, Pitcher TJ, Pauly D (2006b) Fishing down the deep. Fish Fish 7:24-34

Pandolfi JM, Bradbury RH, Sala E, Hughes TP and 8 others (2003) Global trajectories of the long-term decline of coral reef ecosystems. Science 301:955-958

Pauly D, Palomares ML (2005) Fishing down marine food web: it is far more pervasive than we thought. Bull Mar Sci 76:197-211

Pauly D, Christensen V, Dalsgaard J, Froese R, Torres F Jr (1998) Fishing down marine food webs. Science 279: 860-863

Pauly D, Christensen V, Guénette S, Pitcher TJ, Sumaila UR Walters CJ, Watson R, Zeller D (2002) Towards sustainability in world fisheries. Nature 418:689-695

Pitcher TJ (2001) Fisheries managed to rebuild ecosystems? Reconstructing the past to salvage the future. Ecol Appl 11:601-617

Rex MA, Etter RJ (1998) Bathymetric patterns of body size: implications for deep-sea biodiversity. Deep-Sea Res II 45:103-127

Reynolds JD, Dulvy NK, Goodwin NB, Hutchings JA (2005a)

Editorial responsibility: Konstantinos Stergiou (Contributing Editor), Thessaloniki, Greece
Biology of extinction risk in marine fishes. Proc R Soc Ser B 272:2337-2344

Reynolds JD, Webb TJ, Hawkins LA (2005b) Life history and ecological correlates of extinction risk in European freshwater fishes. Can J Fish Aquat Sci 62:854-862

Roessig JM, Woodley CM, Cech JJ, Hansen LJ (2004) Effects of global climate change on marine and estuarine fishes and fisheries. Rev Fish Biol Fish 14:251-275

Sadovy Y (2005) Trouble on the reef: the imperative for managing vulnerable and valuable fisheries. Fish Fish 6 : 167-185

Sadovy Y, Cheung WL (2003) Near extinction of a highly fecund fish: the one that nearly got away. Fish Fish 4:86-99

Sale PF (1977) Maintenance of high diversity in coral reef fish communities. Am Nat 111:337-359

Spalding MD, Ravilious C, Green EP (2004) World atlas of coral reefs. University of California Press, Berkeley, CA

Vila-Gispert A, Moreno-Amich R, Garcia-Berthou E (2002) Gradients of life-history variation: an intercontinental comparison of fishes. Rev Fish Biol Fish 12:417-427

Watson R, Kitchingman A, Gelchu A, Pauly D (2004) Mapping global fisheries: sharpening our focus. Fish Fish 5:168-177

Whitfield AK (1990) Life-history styles of fishes in South African estuaries. Environ Biol Fishes 28:295-308

Winemiller KO (2005) Life history strategies, population relation, and implications for fisheries management. Can J Fish Aquat Sci 62:872-885

Submitted: October 3, 2006; Accepted: February 8, 2007 Proofs received from author(s): March 8, 2007 